\title{
nature
}

biotechnology

\section{The worst of times, the best of times}

\author{
Big pharma should be more proactively investing in cash-hungry public biotech companies.
}

\section{These} hese days, cash is king in the biotech sector. There are the 'withs': most of the top 20 pharmaceutical companies and a few larger biotechs currently sitting on capital reserves of several billion dollars. And there are the 'withouts': an alarmingly large number of public biotech firms with less than a year's cash that are currently gasping for the financial oxygen locked away in deep-frozen tundra of the equity markets. As a result, many biotechs with promising products now face financial oblivion. If the pharmaceutical industry is really serious about fostering a diverse universe of external product opportunities, then it should rethink how it uses some of its cash reserves to invest directly in public biotech firms that currently languish at bargain valuations. In the long term, the result could prove a win-win situation for pharma and biotech alike.

The publicly quoted biotech company sector now finds itself in an extremely precarious situation. According to the Biotechnology Industry Organization, around $38 \%$ of 370 small biotech companies have less than one year's worth of cash. Nearly 100 publicly listed biotechs are operating on less than six months' cash.

Refinancing options are dwindling. The public markets remain shut and convertible debt is increasingly hard to come by. 2008 was the worst fundraising year in the past nine years. Biotech companies raised only $\$ 5.7$ billion from public equity, a 58\% decline from the previous year. And there is little expectation that 2009 will be any better. Compared with the average raised each year by the biotech sector during the previous five years ( $\$ 9.8$ billion), public companies are looking at a shortfall in funding for 2008 of billions of dollars. There is virtually no chance that the deficiency can be made up in increases in other financing sources. The valuations attributed to research collaborations or licensing deals will also be driven down by the general financial slump as witnessed by the fall in the amount of money raised by the biotech sector through partnering in 2008 from $\$ 22.4$ to $\$ 20.0$ billion.

One could argue that devalued biotech companies ought to make attractive acquisition targets. Indeed, in 2008 there was a record number of biotech-pharma mergers and acquisitions (M\&As): $31 \mathrm{com}-$ pared with 19,24 and 23 M\&As in 2007, 2006 and 2005, respectively. However, no one is expecting a dramatic upswing in the capacity of big pharma and biotech to complete more deals or acquisitions in the next 12 months. Although M\&As will mop up a few assets, the bureaucracy associated with such transactions will mitigate against this being a wholesale solution. It's not a matter of cash reservesPfizer has about $\$ 17$ billion in cash reserves and Bristol-Myers Squibb, $\$ 7.2$ billion, for example. The problem is there are only a few biotech companies that big pharma can 'plug and play' into its existing internal strategic R\&D priorities. And Pfizer at least appears set on bulking up with Wyeth rather than investing in biotech small fry.
This brings up another option-private investments in public equity (PIPEs), an off-market transaction in which a company issues new stock to an investment group, usually at a substantial discount to prevailing market rates. Since the end of 2008, many venture capital (VC) funds have been rewriting their investment criteria to allow them to take advantage of distressed public biotech markets. The problem is that the venture capitalists have already been doing this for some time. The well of VC funds for PIPEs and public equity trades is not limitless and investors do not have sufficient management resources to handle the transactions.

Could the pharmaceutical industry or big biotech step in to fill the gap? Perhaps. In December, Novo A/S, which already makes VC investments and holds a controlling interest in Danish biotech giant Novo Nordisk, announced that it had established a \$500 million 'growth equity' fund to do just this type of investment.

The question is will other pharma or big biotech companies follow suit? And if they do get involved, the innate risk-aversion and conservatism of pharma management makes it likely that investments will be selective-for companies with late-stage clinical products. All the other public biotechs - no matter how promising and innovative their phase 1 or phase 2 programs - will be left out in the cold.

In the near term then, the plights of pharma and biotech in the present financial environment could not be more different. Cash-rich pharma can simply hunker down and look forward to occasionally cherry-picking from a smorgasbord of devalued biotech assets for projects to suit its needs. In contrast, public biotech companies face a bleak year ahead. At best, many companies will have to radically restructure, shelve all but one or two key programs or consolidate with another of biotech's walking wounded. At worse, a substantial number of firms will just cease to exist in 2009.

Of course, the pharmaceutical industry is not a charity aimed at saving small biology-based companies. If pharma acts in any sphere, it has to be based on self-interest. But this is not a time for business as usual. With the productivity of internal R\&D programs at pharmaceutical companies continuing to plummet, drug pipelines increasingly empty and a raft of patent expirations on the horizon, a whole swathe of innovative biotech companies simply disappearing will have significant long-term repercussions. The loss of these companies and their products might not be a problem now. But if the current crop of small-cap biotechs with early-phase products does turn into the lost generation, pharma may be looking at a massive new lacuna in its pipelines five years from now.

Pharma needs to pay attention to the plight of current biotech firms and do more to support its drug discovery engine. The time has come for big pharma to ask not what biotech can do for it, but what it can do for biotech. 